\title{
Determination of the input impedance of RFID transponder antennas with novel measurement procedure using a modified on-wafer-prober
}

\author{
M. Camp ${ }^{1,2}$, R. Herschmann ${ }^{1,2}$, T. Zelder ${ }^{1}$, and H. Eul ${ }^{1}$ \\ ${ }^{1}$ Leibniz University of Hannover, Institute of Radiofrequency and Microwave Engineering, Appelstraße 9a, 30167 Hannover, \\ Germany \\ ${ }^{2}$ Smart Devices GmbH \& Co. KG, Schönebecker Allee 2, 30823 Garbsen, Germany
}

\begin{abstract}
This paper shows a new method to determine the input impedance of RFID transponder antennas with a combination of on-wafer-prober and network analyzer. It is shown that the results are in a good agreement with FEM simulations (HFSS) for a large part of the examined antenna structures.
\end{abstract}

\section{Introduction}

Today RFID technology (Finkenzeller, 2003) allows identifying arbitrary objects by implementation of low cost transponders. Use of RFID transponders to the identification of different products with different electromagnetic properties requires the development of new antenna systems which are able to compensate the detuning effects caused by material in the antenna near-field region. For example broadband antenna systems or antenna structures with variable transponder chip positioning on the antenna are promising approaches (Camp et al., 2006). In the second case the chip is implemented according to the desired application for an optimal matching between the antenna and the transponder chip. Numerical simulation methods are suitable for the development of the antenna systems (Herschmann et al., 2005). The verification of the realized antenna impedances must be carried out by measurement because of a variety of production methods and their specific properties used at present for the realization of the antenna structures (Fahlbusch et al., 2006).

Goal of the investigation is the development of a new procedure to measure the input impedance of planar RFID transponder antennas. A modified on-wafer-prober is used to perform the measurement.

Correspondence to: $\mathrm{M}$. Camp

(camp@ieee.org)
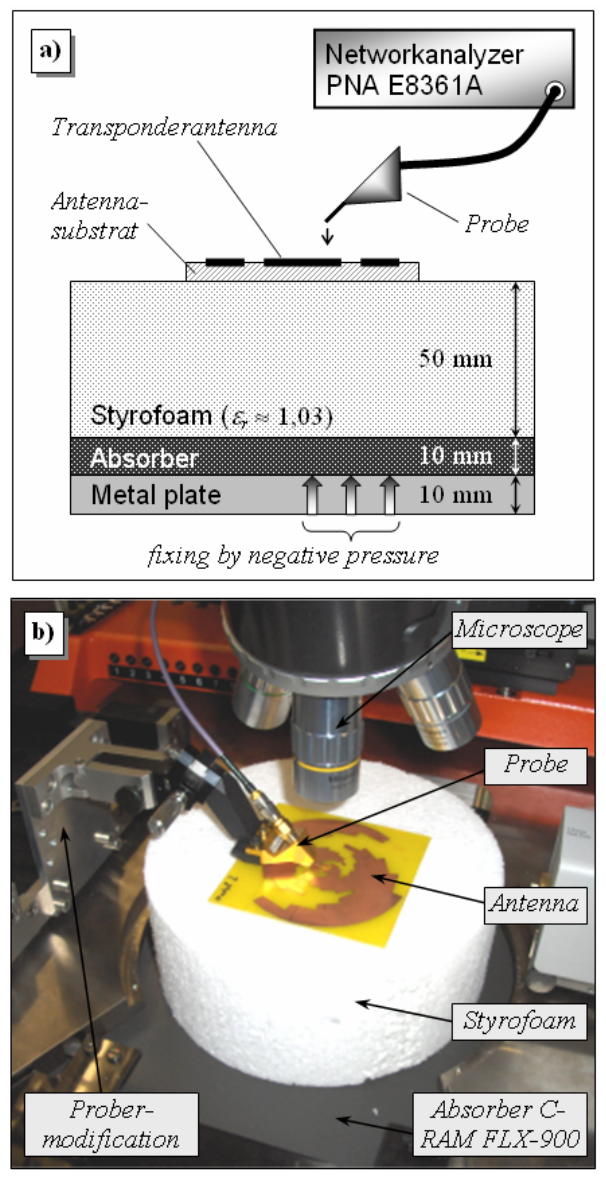

Fig. 1. Measurement setup for the determination of RFID transponder antenna impedances with on wafer prober PA 200 HS (Süss) and network analyzer PNA E8361A (Agilent). 


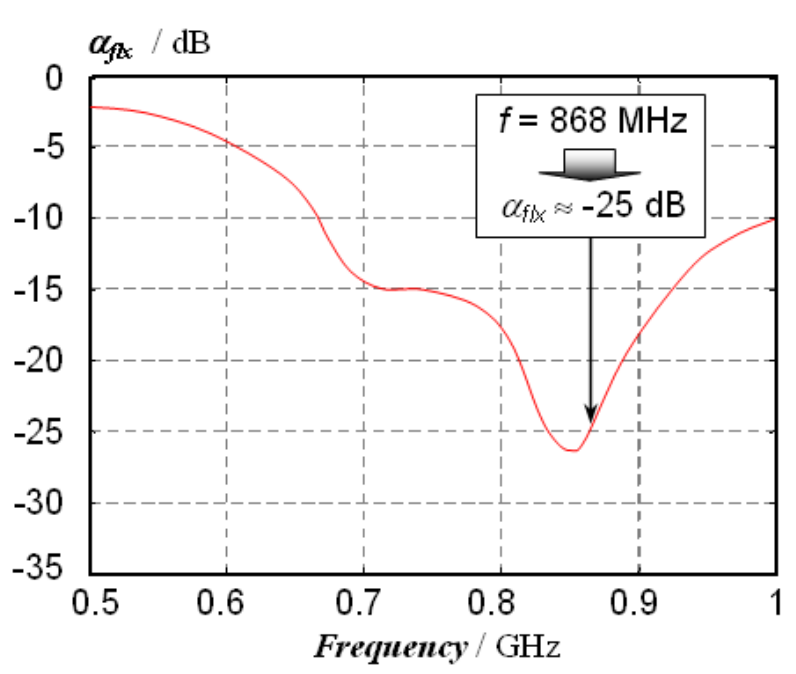

Fig. 2. Reflection loss $\alpha_{\mathrm{flx}}$ of the absorber C-RAM FLX-900.

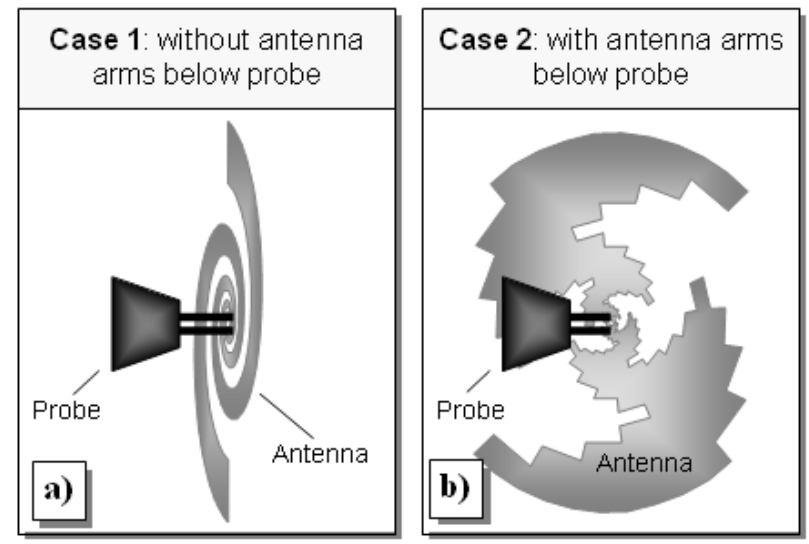

Fig. 3. Distinction of cases: measurement with antenna arms below probe (a) and without antenna arms below probe (b).

\section{Measurement setup}

For the determination of the antenna impedance of different RFID transponder antennas a new measurement procedure was implemented. A modified on-wafer-prober (PA $200 \mathrm{HS}$ ) was combined with a network analysator (PNA E8361A) to perform the measurement. First the probe level of the on wafer prober is elevated by means of mechanical spacers over the Chuck. The Chuck is then covered with absorber material of the type C RAM FLX 900 and is fixed by negative pressure. On the absorber material a styrofoam layer and finally the antenna substrate is placed with the transponder antenna to be measured. That way, the antenna impedance can be measured approximately under free space conditions. Figure 1 shows the principle measurement setup.

The styrofoam layer can alternatively be exchanged with the desired underground material of the antenna. In this case
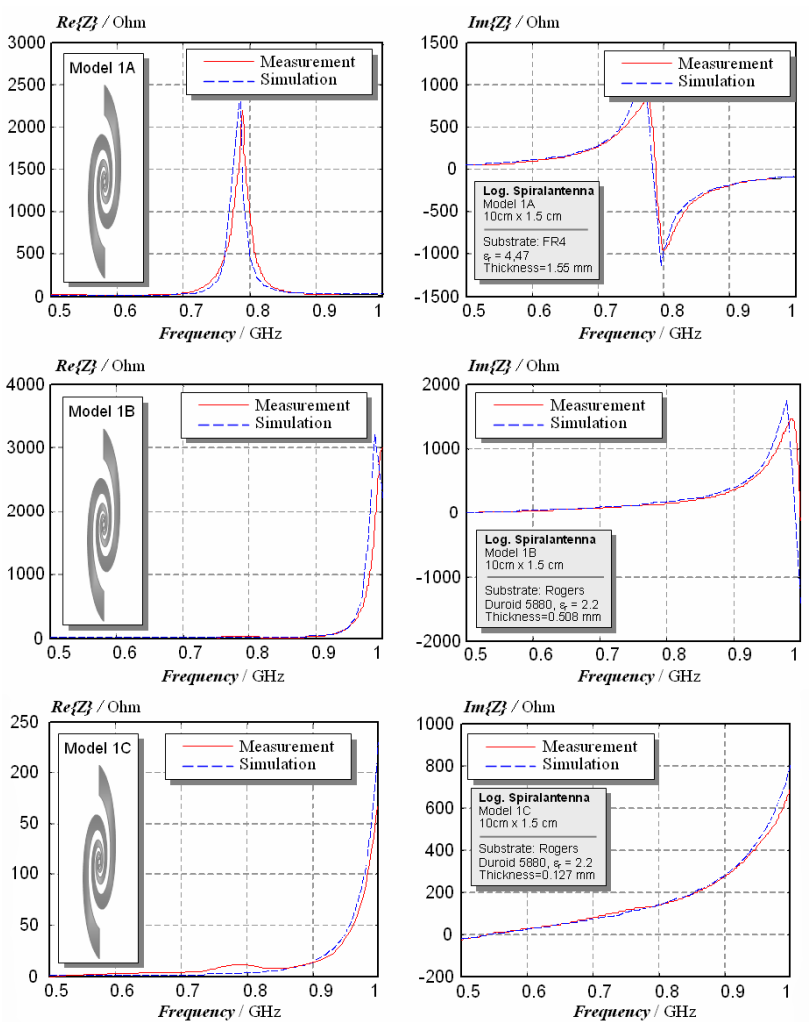

Fig. 4. Comparison of measured and simulated (FEM) antenna impedances of logarithmic spiral antennas on different substrates without antenna arms below probe.

Table 1. Absorber.

\begin{tabular}{|c|c|c|}
\hline Name & Thickness & Specification \\
\hline C-RAM & $3.2 \mathrm{~mm}$ & \multirow{2}{*}{$\begin{array}{l}\text { Lossy, Carbon Filled, Flexible Foam Sheet } \\
\text { Stock }\end{array}$} \\
\hline MT & $0.125^{\prime \prime}$ & \\
\hline C-RAM & $3.2 \mathrm{~mm}$ & \multirow{2}{*}{$\begin{array}{l}\text { High Loss Silicone Rubber Sheet Absorbe } \\
\text { für UHF and Microwave Frequencies }\end{array}$} \\
\hline FF-2 & $0.125^{\prime \prime}$ & \\
\hline C-RAM & $3.2 \mathrm{~mm}$ & \multirow{2}{*}{$\begin{array}{l}\text { High Loss Silicone Rubber Sheet Absorber } \\
\text { for Supression fo UHF Surface Waves }\end{array}$} \\
\hline FDSS & $0.125^{\prime \prime}$ & \\
\hline C-RAM & $3.2 \mathrm{~mm}$ & \multirow{2}{*}{$\begin{array}{l}\text { High Loss Silicone Rubber Sheet Absorber } \\
\text { for Supression fo UHF Surface Waves }\end{array}$} \\
\hline GDSS & $0.125^{\prime \prime}$ & \\
\hline C-RAM & $1.6 \mathrm{~mm}$ & \multirow{2}{*}{ Flexible Magnetic Sheet Absorber } \\
\hline FLX & $0.062^{\prime \prime}$ & \\
\hline
\end{tabular}

it has to be taken care that the thickness of the test material is at least $3 \mathrm{~cm}$ or in addition styrofoam is inserted between absorber and test material to avoid changes of the antenna impedance by the absorber material. With the absorber material used in this investigation (C RAM FLX 900) a reflection loss $<-20 \mathrm{~dB}$ can be achieved in the frequency range from $865 \mathrm{MHz}$ to $870 \mathrm{MHz}$. For other frequency domains absorber 

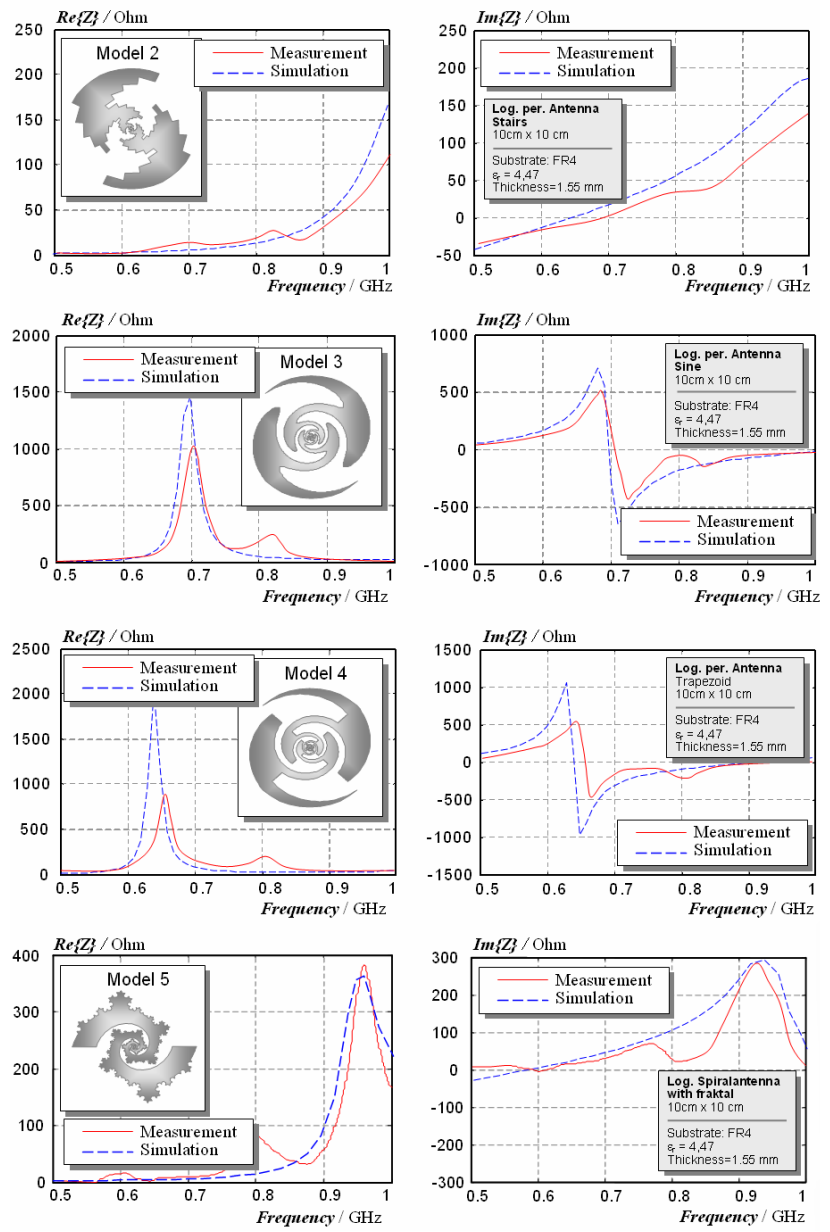

Fig. 5. Comparison of measured and simulated (FEM) antenna impedances of logarithmic periodic antennas with antenna arms below probe.

materials are also available with high reflection losses. The used styrofoam material has a relative dielectric constant of about $\varepsilon_{r} \approx 1.03$ in the frequency range $10 \mathrm{MHz}-10 \mathrm{GHz}$. Figure 2 shows the reflection loss of the absorber material in the frequency range $500 \mathrm{MHz}-1 \mathrm{GHz}$.

Antennas with parts of the antenna body directly under the test probes due to their physical dimensions (Fig. 3) represent an essential problem at the measurement of the antenna impedance with the introduced method. The main metal body of the currently available probes is only a few millimetres above the test level. This results in unwanted coupling effects between the probe and the antenna with deviations of the measured antenna impedance.

\section{Measurement results}

Figure 4 show the measurement results of logarithmic spiral antennas on different base substrates in comparison to sim-

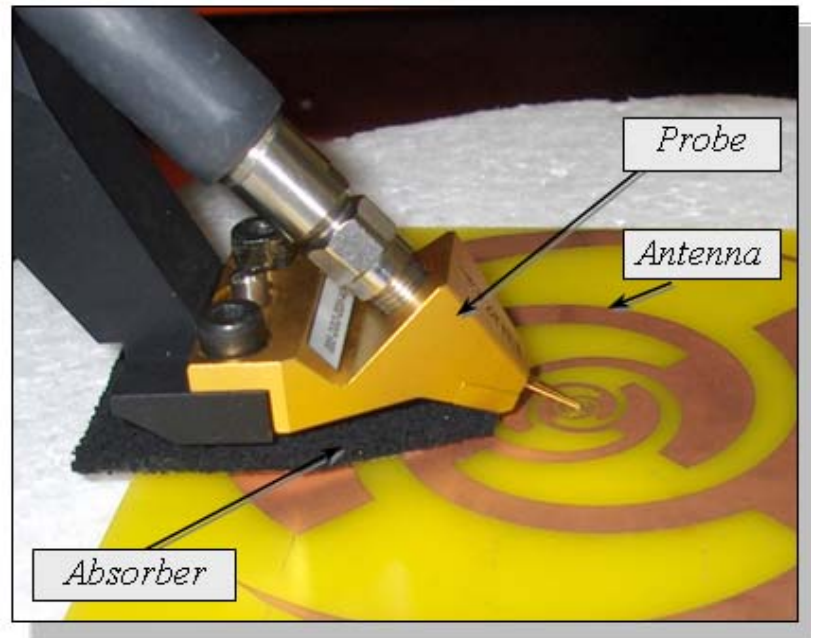

Fig. 6. Measurement setup with absorber between probe and antenna.
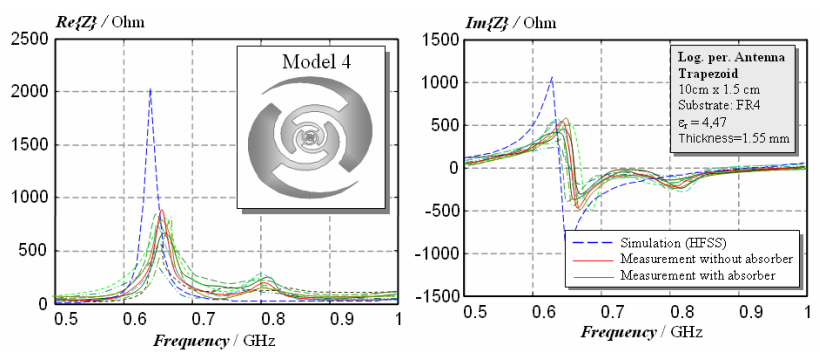

Fig. 7. Measurement of the antenna impedance with different absorber materials between probe and antenna.

ulation results obtained with the programme HFSS (FEM). The simulation and measurement results are generally in an good agreement. Figure 5 show the results of different logarithmic periodic antennas with large areas of the antenna arms below the probes. Due to unwanted coupling effects deviations between measurement and simulation are visible. Further a resonance appears by the measurement equipment at all examined antennas in the area of $810 \mathrm{MHz}$.

To reduce the influence of the probe, different absorber materials were placed between probe and antenna. Figure 5 shows the measurement setup with the absorber C-RAMMT26/PSA between probe and a logarithmical periodical antenna with trapezoid base function. Table 1 shows the absorber materials used.

The problem using absorber material is the low distance between probe and antenna of about $4 \mathrm{~mm}$. For this reason only thin absorber sheets can be placed between probe and antenna. Further the antenna impedance is affected by the absorber material due to the close distance. Figure 7 shows the change of the impedance of a logarithmical periodical antenna with trapezoid base function e.g. The absorber 
materials represented in Table 1 were used. With none of the materials used, a clear improvement of the measurement result of the antenna impedance could be reached.

\section{Conclusions}

Goal of this investigation was the development of a new procedure to measure the input impedance of planar RFID transponder antennas. A combination of an modified onwafer-prober and a network analyzer was used to perform the measurements. The comparison of the measurement results with results achieved by numerical field simulation methods (FEM) has shown, that for a large part of the examined antenna structures the results are in a very good agreement. Deviations between simulation and measurement results are mainly due to unwanted electromagnetic coupling between antenna and measurement probe at antenna structures with extensive metallic area below the probe.

\section{References}

Finkenzeller, K.: RFID Handbook, John Wiley and. Sons, New York, New York, 2003.

Camp, M., Herschmann, R., Fahlbusch, T., Eul, H., and Overmeyer, L.: Optimierung der Anpassung zwischen integrierter Schaltung und Antennensystem bei UHF-RFID-Transpondern durch variable Chippositionierung auf der Antenne, ITG-Fachbericht 195, 2. Workshop RFID, VDE-Verlag GmbH, Erlangen 2006, 4-5 Juli, ISBN: 978-3-8007-2976-0, 2006.

Herschmann, R., Camp, M., and Eul, H.: Design und Analyse elektrisch kleiner Antennen für den Einsatz in UHF RFID Transpondern, Kleinheubacher Tagung (URSI), 26-30 September 2005, Miltenberg, Germany, Sitzung B.3: Sensorik durch elektromagnetische Felder und Wellen, 2005.

Fahlbusch, T., Herschmann, R., Camp, M., Meier, D., and Overmeyer, L.: Verfahren zur Produktion von UHF-Labeln auf laserstrukturierten Substraten, ITG-Fachbericht 195, 2. Workshop RFID, VDE-Verlag GmbH, Erlangen 2006, 4-5 Juli, ISBN: 9783-8007-2976-0, 2006. 